In: Forgas, J. P., Crano, W., \& Fiedler, K. (2023). The social psychology of insecurity. The 24th Sydney Symposium on Social Psychology. Taylor \& Francis.

\title{
Strategy, Trust, and Freedom in an Uncertain World
}

\author{
Joachim I. Krueger \\ Brown University, USA \\ David J. Grüning \\ Heidelberg University, Germany \\ GESIS - Leibniz Institute for the Social Sciences, Germany
}

\author{
Correspondence: \\ Joachim I. Krueger \\ Department of Cognitive, Linguistic \& Psychological Sciences \\ Brown University, Box 1820 \\ 190 Thayer Street \\ Providence, RI 02912 \\ Phone: (401) 863-2503 \\ E-mail: Joachim_Krueger@Brown.edu
}

Keywords: strategic reasoning, freedom, uncertainty, rationality, randomness

Note. We thank George Cockcroft, a.k.a. Luke "The Dice Man" Rhinehart for showing us the joys of randomness in a deterministic world, Joe Forgas for adding nuance to our views on existential dread, and Klaus Fiedler for scattering our epistemic doubts when declaring that the finding "had to be so." Anna Cohenuram and Cliff Dutton provided helpful feedback on a draft of this chapter. 
Uncertainty becomes insecurity if we allow it to upset us. - Hoca Camide

Humans live their lives suspended between states of knowledge and ignorance. Knowing or hoping - that knowledge is power and that ignorance is no bliss, most humans seek knowledge, and they do so in part because knowledge reduces states of insecurity (see also von Hippel, this volume). This being said, it is noteworthy that there are also instances where it is wise to choose ignorance (Krueger et al., 2020; Hertwig \& Engel, 2020), a surprising qualification to the general epistemic drive to seek knowledge to which we shall return.

The quest for knowledge takes various forms. In the simplest case, there are risks, that is, known probabilities with which certain outcomes will occur, and there are methods to manage these risks (Gigerenzer, 2015). In more complex cases, there is uncertainty, that is, states in which the probabilities of the outcomes are not known (Gigerenzer, 2020; Knight, 1921). States of uncertainty are most likely and most poignant when they depend on the unpredictable behavior of other people (Gigerenzer, 2022). Such unpredictability is present especially when these others have their own strategic interests and when they are able and willing to deploy the arts of deception. These limitations to knowing what will happen can make the soundest mind feel insecure. Yet, although feelings or insecurity are generally unpleasant, they may be psychologically useful (see also Fiedler \& McCaughey and Kruglanski \& Ellenberg, this volume); again, a point to which we shall return.

In this chapter, we explore four ways in which uncertainty and its concomitant states of insecurity are tractable challenges. In the first section, we approach this challenge from a gametheoretic perspective. A simple guessing game serves as the context for the exploration of biased and optimal strategies when a player is faced with an opponent's unknown choice. We show that a theory of mind and social projection in particular can clear some of the fog of uncertainty (see for other examples, Forgas, this volume; Kreko, this volume; Krueger \& Grüning, 2021; Krueger et al., 2022; van Prooijen, this volume). In the second section, we turn to the trust game, where uncertainty is amplified due to an interplay between strategies of coordination and discoordination. We show that acts of trust can reduce uncertainty by allowing the trustor to estimate the prevalence of trustworthiness more accurately (see also van den Bos, this volume). In the third section, we explore 
the association between folk beliefs about free will and individual differences in uncertainty intolerance. Furthermore, we ask how free will believers compared with skeptics are socially evaluated (Krueger et al. 2020). In the last section, we explore how human freedom may grow from a strategic randomization of options and actions, that is, from a stance of self-imposed deliberate uncertainty. Whether such strategies reduce or increase a person's sense of insecurity likely depends on the person's character. Freedom, we suspect, is not for everyone.

\section{Strategy and uncertainty}

Individuals need to think strategically when their interests conflict with the interests of other, also potentially thoughtful, individuals (Krueger, 2007a). If the unpredictability of the natural or the artificial world did not offer enough risk and uncertainty, strategic competition between reasoning agents adds a host of motives that make success difficult. The complexity of social interaction is liable to induce feelings of stress and insecurity. This disutility of affect together with potentially pointless attempts to reason through the entire strategic event horizon suggest there is wisdom in letting go (see also Kruglanski \& Ellenberg, this volume). The famous Prussian strategist Helmuth von Moltke the Elder noted that calculated planning can go up to the first contact with the enemy. From then on, one must assume that the opponent is equally able to anticipate strikes and counterstrikes. Ultimately, flexibility, luck, and the weather are decisive.

What then is the hallmark of strategic reasoning? Fiske and Taylor (1984) noted that 'other people think back,' and that this thinking back is what separates social cognition from other types of cognition. What is more, people know that other people think back and that they know that they know et cetera et ad nauseam. But perhaps there need not be any nausea. If it is true that an infinite recursion of the 'I-know-you-know-I-know' variety might lead to insecurity and despair, it is also true that few mortals can dive deeply into the rabbit hole of reflected thought. Insecurity can be managed by limiting recursive thought or by deliberately choosing to act randomly.

To explore these issues, we used a thought experiment described by Dixit and Nalebuff (2008) as our starting point. In that experiment, a participant must try to guess a number randomly drawn from the range of 1 to 100 . If the first guess is correct, there is a premium of $\$ 100$. Otherwise, they is only a note saying whether the target number is larger or smaller than the guess. If the second 
guess is correct, the premium falls to $\$ 80$. If the guess is wrong again, the game continues until a guess is correct or the money has run out, whichever comes first. The optimal strategy is to always guess the middle number of the available range, which minimizes the residual range. The social version of this game is more complex. Here, a human chooser has selected the number to be guessed, which raises the question of whether the split-range strategy is still optimal. The guesser must worry that the chooser anticipates this strategy and therefore avoids the numbers this method generates. Can the guesser account for the chooser's ability to anticipate their own guesses? And what is a guesser who is mindful of this complication to do?

Dixit and Nalebuff (2008) argued that the first, engineering, version of the game imposes a tractable risk, whereas the social version creates uncertainty as the guesser and the chooser seek to anticipate each other's moves. As there are no logical grounds for either player to assume that they are able to think one step further than the opponent, it appears that the game's mentalizing element collapses with the result that the chooser resorts to selecting the target number randomly and the guesser, who anticipates this, returns to the split-range method, which is optimal under this circumstance. All told, the guesser in this strategic game may not be worse off in terms of the game's expected value, but will be more distressed than a guesser in the engineering version of the game. The same holds true for the chooser. If they had a choice which version of the game to play, both players might prefer the engineering version in order to avoid the uncertainties and insecurities that come with the social game. As we will see, however, most respondents ignore this advice, thereby revealing a fundamental social preference. Perhaps it is more fun to play against a person than against a robot, the insecurities notwithstanding. If victory is sweeter and defeat is bitterer, social games expose a titillating kind of insecurity-seeking.

Now consider then a simplified one-shot version of this game. The chooser picks a number from 1 to 6 and the guesser tries to match it. If the numbers match, the guesser receives 60 Forint, otherwise the chooser receives 12 Forint to equalize the game's expected value. When both players are invited to actively think of a number and consider what the other player may think (they think, etc.) the game is strategic. If, however, a player casts a die to obtain a random number, the game is 
aleatory and not strategic. Any mentalization about the other player's approach to the game evaporates.

We showed research participants four versions of this game (Grüning \& Krueger, 2021), constructed to constrain players to either actively think about a number or randomly select one. Participants then indicated how much they would pay for the right to play the game as a guesser. The critical result, with data pooled over two experiments was a significant interaction effect. As shown in Figure 1, if the chooser thought of a number, participants were willing to pay more if they could also think of a number, $d=.36$. When the chooser was said to randomize the number selection, the difference was trivially small, $d=.13$.

\section{Figure 1}

Guesser's willingness to pay when thinking or randomizing vs. a thinking or randomizing chooser
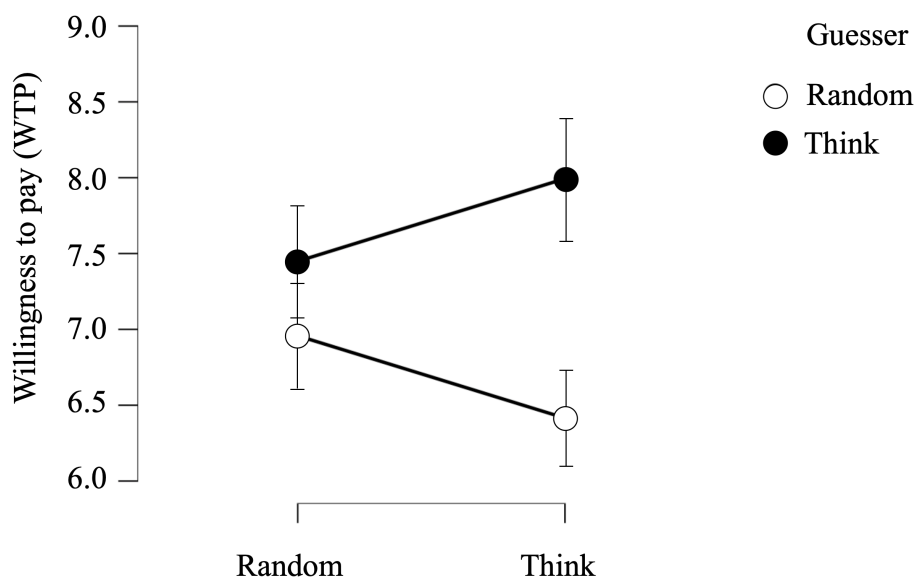

Chooser

This pattern is reasonable if people, regardless of their role, are biased in their selection of numbers. If a chooser is more likely to think of a mid-range number than of a high or a low number, guessers can improve their chances of matching that number simply by choosing the number that comes to their own mind. That is, they can act strategically without directly trying to replicate the chooser's reasoning. Using the heuristic or social projection, they can capitalize on the value their own ideas have in predicting the ideas of others (Krueger, 2007b). Choosers who are metacognitively rational and not overconfident know this (Moore, 2020) and randomize (e.g., by 
throwing a die) even when they have the privilege to think about what number they wish to bet on. They rationally refuse to think.

Randomization is a minimax strategy guarding against being exploited, but it does not improve the chooser's prospects of winning. Our data suggest that in the role of choosers, participants also prefer to think of a number when the other player thinks of a number (Grüning \& Krueger, in preparation). Because only guessers are rewarded when numbers match, the think-think scenario can be advantageous for them and they seem to be confident in their ability to utilize this potential. In contrast, a preference for the think-think scenario undercuts the choosers' material interest. Respondents do not seem to realize this. Believing in the superiority of their own strategic insights, they end up hurting themselves.

Figure 2 shows that thoughtful number generation is biased toward the mid-range (Grüning \& Krueger, 2021). When participants were instructed to predict the least popular number generated by the sample of participants given the same instructions, they preferred high or low numbers (dashed lines). Whereas the first result demonstrates the familiar population stereotype in number generation, the second result reveals myopic meta-cognition. Respondents appeared to think just one step ahead without realizing that others do too. That is, they correctly understood the population stereotype favoring mid-range numbers, and they acted in contradistinction to it. They failed to see, however, that other participants do the same. This is an interesting result because it shows that social projection is myopic. Participants projected only one step ahead and failed to projectively realize that others would do the same. They thought they could outsmart others. Had they understood the recursive nature of the number generation task, they would have randomized.

\section{Figure 2}

Frequencies of chosen numbers when instructed to select the most vs. least popular number from 1 to 6 


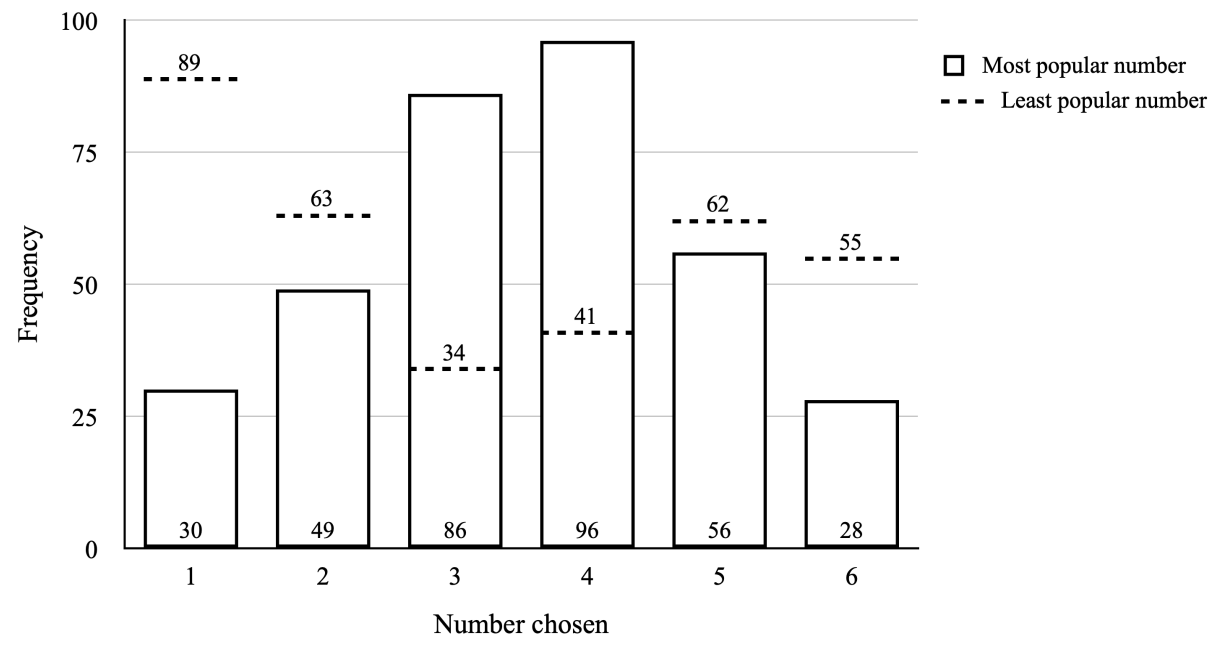

These findings shed light on uncertainty aversion (vs. tolerance) and the psychology of insecurity. Whereas game theory uses randomness to find Nash equilibria when there are no dominant strategies, the theory treats all players the same, at least if the payoffs are symmetrical (von Neumann \& Morgenstern, 1947). Game theory teaches players how not to get exploited; it does not teach them how to beat an opponent who is being coached by the same game theorist. After John von Neumann proved that there is no winning strategy in the game of rock, paper, scissors (Fisher, 2008), cunning gamers understood that in order to win, they have to step outside of the game (Schelling, 1960). History teaches that those who are the first to change the rules stand to win. Epaminondas of Thebes routed the Spartans at Leuctra when he flouted convention by deepening the left wing of his phalanx. Likewise, Field Marshal Moltke invented new stratagems and won. His nephew, Moltke the Younger did not and his armies were thrown back at the River Marne.

Surprise is self-eliminating. Once a new trick has been played, it is no longer new. The element of surprise has to continually renew itself, a point that is as trivial as it is profound. The search for an effective surprise does not change the self-limiting logic of recursive mentalization. Any would-be innovator must worry about opponents have even newer tricks of their own. The possibility of being surprised in a strategic environment creates insecurity, and it constantly renews itself.

The guesser's challenge in the number game is discoordination. Although the guesser seeks to find a matching number, the chooser wants to foil the effort. Discoordination entails uncertainty 
and perhaps insecurity. Less obviously, games of coordination do the same. Suppose both the chooser and the guesser get rewarded if their numbers match. The two players are, as it were, members of the same team, but there is no reason to think that they could do better by engaging in so-called "team reasoning" (Gold \& Colman, 2020) than by social projection alone, that is, by picking a number that comes to mind and assuming that this might be the number that also comes to the other player's mind. With team reasoning, players would think of a number and, assuming that the other player is also a team reasoner, think that the other would also think of that number. Then, they would, in an exercise of pointless recursion, redouble their commitment to that number. If projection is a sufficient condition of team reasoning, it is unclear how team reasoning proper can improve over the advantages already bestowed by social projection (Krueger, 2014).

We may ask if a coordination version of the number guessing game is more attractive than the conventional discoordination version. We suspect that a failure to coordinate hurts more than a loss in a competitive discoordination game. In a coordination game, there is no point in blaming an opponent who wants to win. The guesser may only fault the other for not trying hard enough to achieve a common goal. Disappointment in the low performance of a presumed ally is akin to a loss of trust; it is more painful than the upset felt at the expectedly high performance of a known foe.

\section{Trust and insecurity}

The number guessing game, like many behavioral dilemmas, is symmetrical in the sense that both parties act without knowing the other's strategy. Both have to simulate it, and simulate the other's simulation of it, and so forth. Certain sequential games break this symmetry. Here, only the first mover faces the strategic challenge of figuring out what the other will do. The second mover simply needs to respond to the first and play their preferences. If the game allows foreplay, the second mover may attempt to signal certain preferences to elicit the most favorable opening from the first mover (Karakowsky et al., 2020).

This sequentiality complicates the uncertainty faced by the first mover. Consider the trust game (Berg et al., 1995). The trustor has a small endowment, say 10 Forint, in hand and a choice between keeping it and transferring it to the trustee. If the money is transferred, it triples in value (other multipliers have been used). In turn - and the trustor knows this - the trustee then has a choice 
between keeping the money and splitting it with the trustor, in which case both end up better off (Evans \& Krueger, 2009). Being the second mover, the trustee is free to act on their social preferences. If there is foreplay, and the trustee has an opportunity to signal trustworthiness or make promises, they might do so if they think the trustor will not consider such talk to be cheap. One might say that the trustee must trust the trustor to trust, but this is not trust proper unless the trustee invests resources that might be lost if the trustor fails to trust.

The trustor faces a more taxing psychological challenge because it is not known whether the trustee is poised to play a coordination game or a discoordination game, that is, whether the trustee will reward or punish the trustor's trust (Krueger et al., 2008). Not knowing what kind of game they are in, trustors experience greater uncertainty than players in the numbers game. As the trust game sets the stage for conflicting emotions, it is likely that trustors also experience greater insecurity than players in a number guessing game (see also Kruglanski \& Ellenberg, this volume). Game theorists refer to behavioral choice options as 'strategies.' Trusting is a strategy, and so is distrusting. Recall that in the numbers game, a guesser can reduce uncertainty with the split-range strategy. As we shall see, trustors may also try to reduce uncertainty, and this could be a reason for trusting in the first place. The trustee has no uncertainty once the trustor has moved.

The trustor faces the challenge of reducing uncertainty by predicting the trustee's trustworthiness via repeated updating and cue utilization (Grüning \& Salmen, 2021). Of course, trustors can eliminate uncertainty entirely by keeping the money, that is, by claiming game-theoretic rationality or by appealing to biases such as loss aversion, the certainty effect, or the endowment effect. A more enlightened trustor, however, may realize that there is an opportunity to learn from trusting and to thereby reduce uncertainty. At the limit, a trustor who always trusts in a first encounter can eventually generate a highly accurate estimate of the prevalence of trustworthiness in a population. In contrast, someone who never trusts remains locked in a worldview of suspicion. As a consequence, a paranoiac is not only lonely and highly insecure, but also ill-informed about others.

Trustors who accept the social risk of trusting will sometimes be disappointed. By statistical necessity, very high estimates of trustworthiness likely overestimate the actual prevalence of trustworthiness, whereas very low estimates of trustworthiness underestimate this prevalence. Since 
low expectations of trustworthiness will often end in decisions not to trust, these expectations cannot be updated with experiential data; the estimates of trustworthiness remain too low. Conversely, high expectations are updated by experience and can thereby attain a high level of calibration (Moore, 2020). When the expectations of optimistic and pessimistic trustors are pooled, it will turn out that the population of trustors in the aggregate underestimates the level of trustworthiness in the population (Denrell \& Le Mens, 2012; Prager et al., 2018). We are, in other words, more distrustful than we need to be (Evans \& Krueger, 2016).

How much can optimistic trustors learn from accepting the risk of defection and betrayal? We modeled the trustors' information gain with Bayes's Theorem and by assuming that an optimistic trustor begins with a prior probability of the trustee being trustworthy. Let this perceived prior probability of trait trustworthiness, $\mathrm{p}(\mathrm{T})$, be greater than .5 , for otherwise few trustors would trust. The trustor updates $\mathrm{p}(\mathrm{T})$ depending on whether the trustee rewards trust, $r$, or betrays it, -r. Let us also assume that the trustor is interested in the trait of trustworthiness and knows that trustworthy trustees (for whom $\mathrm{p}(\mathrm{T})$ is high) on occasion fail to reward trust and that untrustworthy trustees (for whom $\mathrm{p}(\mathrm{T})$ is low) sometimes reward it. The trait of trustworthiness translates into corresponding behavior with a bit of unreliability or with trembling hand as it were. For simplicity, we assume that $\mathrm{p}(-\mathrm{r} \mid \mathrm{T})=1-\mathrm{p}(\mathrm{r} \mid \mathrm{T})$

Before the trustor trusts, the degree of certainty is the probability of facing a trustworthy other, $\mathrm{p}(\mathrm{T})$. If trust is rewarded, the posterior probability is $\mathrm{p}(\mathrm{T} \mid \mathrm{r})$; after betrayal, it is $\mathrm{p}(\mathrm{T} \mid-\mathrm{r})$. We assume that the former occurs with the prior probability of trust, $\mathrm{p}(\mathrm{T})$, and the latter with its complement, $1-\mathrm{p}(\mathrm{T})$. The change from prior to posterior certainty is written as

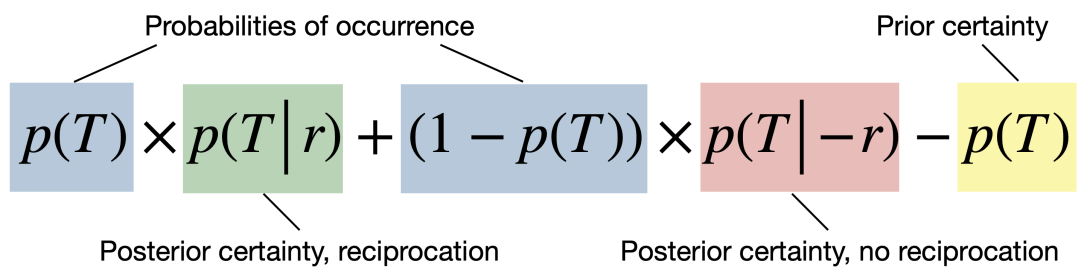

where the subtracted term is the prior degree of certainty. 
Figure 3 shows the net increments in perceived trustworthiness, that is, the difference expressed in the formula, for $.6 \leq \mathrm{p}(\mathrm{T}) \leq .95$. Differences in the trustee's reliability (i.e., 1 - tremor) are shown in the 5 concave functions.

\section{Figure 3}

Association between prior certainty, $\mathrm{p}(\mathrm{T})$, and posterior gain of certainty

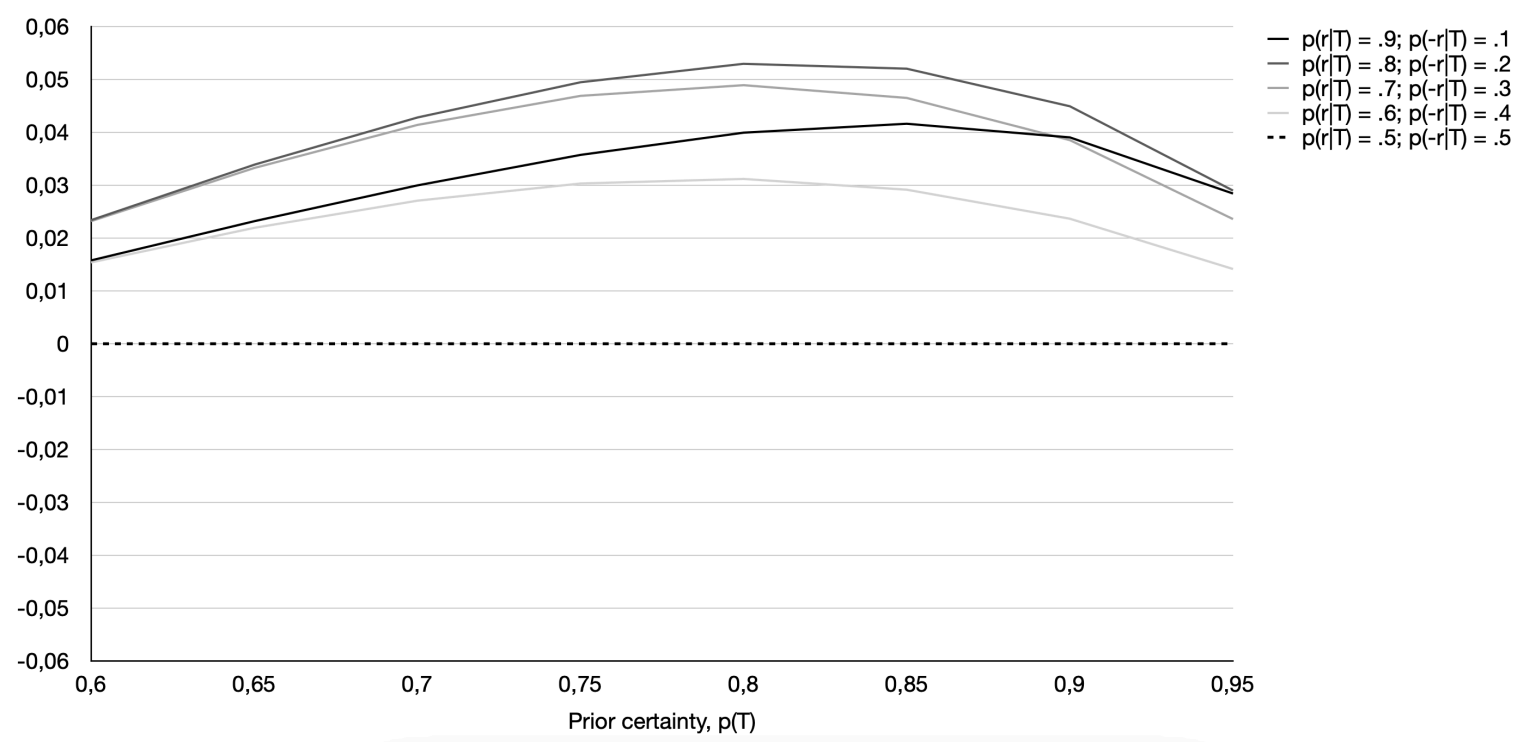

Besides the finding that the consequences of trusting behavior increase the trustor's certainty regarding trustworthiness, there are two nonlinearities. First, the magnitude of the certainty gain is largest if the prior expectation of trustworthiness falls in the midrange between maximum uncertainty $(p(T)=.5)$ and maximum certainty $(p(T)=1)$. Second, this effect is stronger for high levels of trait-behavior reliability $(\mathrm{p}(\mathrm{r} \mid \mathrm{T})=.8)$ than for very high or low reliability. These are higherorder uncertainties, which the trustor in the street may not be cognizant of, but they are mathematically describable.

We now see that there is a hitherto neglected reason for why people trust: they stand to learn information about their social world, information that would remain hidden if trustors refused to take social risks (see also Hirschberger; Hogg \& Gaffney; van den Bos, this volume). To trust is to forage the social world for productive patches of exchange (Stephens et al., 2007). Under the conditions we modeled, trustors will gain, despite occasional setbacks, confidence that others are trustworthy and their estimates of the prevalence of trustworthiness gain precision. Critically, however, the first of 
these gains is not obtained when trustors set out with inflated estimates of trustworthiness. Here, repeated experience with a mix of trustworthy and untrustworthy trustees will result in updated beliefs that are lower than the prior beliefs. The logic of regression requires this (Fiedler \& Krueger, 2012). This is why parents teach their children not to trust others indiscriminately.

Trust is multi-determined. Material and informational interests affect it. A recent study sheds light on how trustors strategize (Evans et al., 2021). Trust increased with perceived trustor-trustee similarity, and three psychological variables mediated this effect. Similarity heightened the expectation of reciprocity, increased liking of the trustee, and increased a sense of moral obligation to trust. Only the first mediator, expectation, picks up on the experience of uncertainty and the hope for its reduction. This is why expectations should be most responsive to experience. Interpersonal liking should follow such that rewarders are liked more than betrayers irrespective of self-other similarity (Clement \& Krueger, 1998; see also Arriaga \& Kumashiro; Mikulincer \& Shaver, this volume). Finally, normative beliefs regarding one's obligation to trust should be most resistant to learning from experience, which is why trustors with strong normative beliefs are most vulnerable to exploitation. In conclusion, there is a tension between the informational benefits of trusting and the dangers of principled or consistent trust. Trust remains an irreducible social dilemma; it can be described, modeled, and managed, but it cannot be eliminated (Krueger \& Evans, 2013).

\section{Free will belief, determinism, and uncertainty}

Players in the numbers game and in the trust game might experience their own choice and agency as freely willed. 'I could,' they might say, 'have acted differently.' A cheeky response to this assertion is 'Why didn't you?' Such rhetoric would give no comfort to either the free will believer or the skeptic. If the chooser had chosen differently, the same claim and the same response could be made. It's much like arguing whether the number 3 is random. Any individual act or event in time eliminates its alternatives, and this is so both under the doctrine of free will and under the doctrine of determinism. It is so even under the doctrine of randomness (MacIntyre, 1957). When the die falls to show the number 6, it may be said that things could have been different. But they weren't. Yet, the human ability to engage in counterfactual ideation is critical for many reasoning tasks (Dawes, 1988), and for causal inference in particular (Morgan, 2014; Roese, 1995). When counterfactuals are 
marshalled to defend the doctrine of free will, we submit, the ability to reason about that which did not happen is being abused to support an absurd claim.

Determined critics of the belief in the freedom of the will see this belief as equivalent to visual illusions (e.g., Pinker, 2021). It may seem that we will our actions and that we could have acted differently, but no science supports this view (Seth, 2021). As Emil Cioran (2012/1973, p. 92) put the dilemma: "I feel I am free but I know I am not" (italics in the original). Still, the visual illusion analogy has its limitations. Whereas illusions, such as Doktor Poggendorf's, fool most of us, many people reject the libertarian doctrine of free will, as documented by survey research into individual differences in the degree to which people embrace free will beliefs (Grüning \& Krueger, in preparation; Nadelhoffer et al., 2014; see also Sarkissian et al., 2010; Genschow \& Lange, 2022; Westfal et al., 2021). We must therefore ask if the belief in the freedom of the free will offers psychological benefits to some people.

One indication of free will belief's functionality is its correlation with certain religious values. Some Abrahamic religions, such as Judaism (Schimmel, 1977) and Catholicism, insist on the freedom of the will, which allows them to view transgressions as blameworthy and punishable (see also Fiske, this volume, for similar patterns in other cultures). Ironically, however, the presumed necessity of free will for attributions of responsibility and the delivery of just deserts may itself be a matter of perceptual illusion. Calvinists, for example, get on without the notion of free will and without having stopped to punish transgressors (Krueger, in press). Granted, some of these ideas are matters of theological dogma; ordinary people show greater flexibility in what they profess (Murray et al., 2021).

An hypothesis regarding the psychological functionality of free will belief is that it is linked to the experience of - and aversion to - uncertainty. To explore this possibility, we asked 62 participants to respond to some items from the Free Will Inventory (FWI; e.g., "I always have the ability to do otherwise" Nadelhoffer et al., 2014) and the Intolerance of Uncertainty Scale (IUS; e.g., “Unforeseen events upset me greatly," Buhr \& Dugas, 2002). The questions were framed to refer to the participants' personal perspective (see Appendix B for all items). We found a small positive correlation, $r=.24$, suggesting that stronger free will beliefs are associated with a lower tolerance of 
uncertainty. In other words, a belief in the freedom of the will may protect the believer from facing some of the uncertainties of human existence or the uncertainties that come from interactions with other humans who prefer to make themselves unpredictable.

As part of the functionality of social beliefs is grounded in the reputations they support, we asked a sample of observers to judge target individuals in terms of their competence and their morality given the targets' beliefs about free will (weak vs. strong) and their degree of uncertainty aversion (low vs. high; see also Hogg \& Gaffney, this volume). We presented four target person profiles to each of 180 participants, who then rated each target on their competence (competent, intelligent, rational) and morality (benevolent, moral, principled).

Figure 4 shows that a target expressing a strong belief in free will was rated both as more competent, $d=.35$, and as more moral, $d=.67$, than a target expressing a weak belief, suggesting a strong positive halo effect. "People that believe in their freedom to choose," respondents seem to be inferring, "have to be capable of doing so in the first place and they are, then, also aware of the responsibility for their actions."

\section{Figure 4}

Participants' rating of the competence and morality of a target person that displays a high vs. low degree of belief in free will

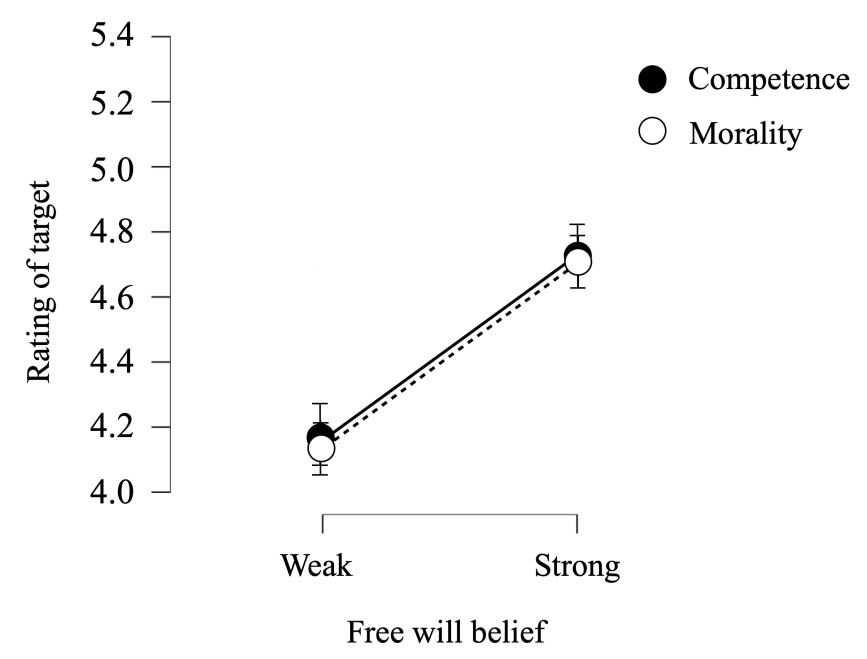

Figure 5 shows the results for uncertainty aversion (a facet of uncertainty intolerance). This belief was only associated with judgments of competence, $d=.35$, but not with judgments of 
morality. Perhaps, people, in a reverse inference, believe that an uncertain mind is an incapable mind. Those who are not able or skilled have to deal with more uncertainties in life. For the moral virtue of a person their uncertainty aversion is irrelevant, a null result that is hard to interpret.

\section{Figure 5}

Participants' rating of the competence and morality of a target person that displays a high vs. low uncertainty intolerance

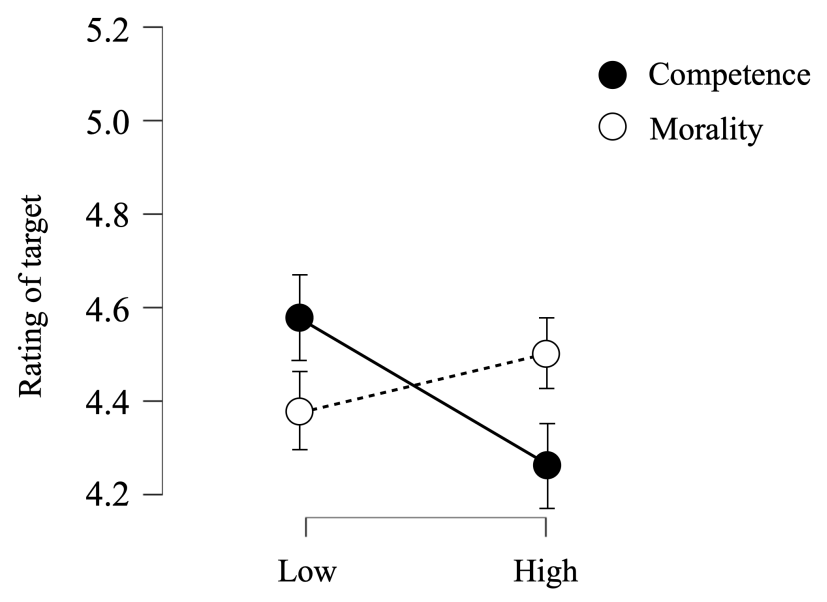

Uncertainty intolerance

A believer in the freedom of the will appears as more competent and more moral than a skeptic, whereas an uncertain person signals incompetence but lacks definite cues about moral virtues like their benevolence toward others.

\section{Randomness and resistance}

It is not for us to resolve the free-will debate (see Pleasants, 2019, for a balanced philosophical review). As definitive proof in its favor is lacking, we might either settle for a faithbased belief in free will or look elsewhere to ground human freedom. The former strategy does not heal our insecurities; instead, it might deepen them. While Pyszczynsky (this volume) discusses selfhandicapping as a means to reduce personal responsibility in the face of uncertainty, we now consider a radical alternative: freedom through randomness. The time has come to meet the Dice Man.

George Cockcroft, under the pen name Luke Rhinehart (1971), related the adventures of his hero, a New York City psychiatrist turned aleatorian. Disillusioned by the ego psychology and the 
human relations movement of his day, which urged clients and encounter groupies to discover their one true self, Rhinehart took a different tack. Instead of one true self, he reasoned, there is an assemblage of egos, desires, tendencies, and potentialities vying to be expressed (Seth, 2021). The most dominant ego - tautologically - wins, and when it wins repeatedly, it creates the illusion of oneness (Krueger et al., 2017). Meanwhile, the other egos see their wishes ignored or suppressed. The result is civilized discontent and the neurotic feeling that something is amiss. Ödön von Horváth (1929/1978, p. 67) captured this sentiment when lamenting that "Ich bin nämlich eigentlich ganz anders, aber ich komme nur so selten dazu." [I am actually quite different, but I just rarely get around to it].

Rhinehart's solution was as ingenious. He opened the door to randomness to give his alter egos a chance. Beginning with a single die and one toss, he laid out several options for action and their probabilities. For example, he would take the trash out if the die yielded a 1 or a 2 , and otherwise watch football. Things got complicated - and more fun - fast. Rhinehart introduced variable odds involving several dice, and he included risqué behavioral options that had some motivational appeal, such as having a go with pretty Arlene upstairs. His only rules were that there had to be some otherwise suppressible wishes (though they would be assigned long odds), and that, once the dice had spoken, he had to act as they said. The Dice Man thus began to explore himself with a precommitment to obey chance. He expanded his within-person variance of behavior, and he broke the causal link between intention - or a single will - and behavior.

The Dice Man solved the problem of the freedom of the will by breaking the box. He proved that he could have acted otherwise, that is, if the dice had yielded different numbers, but this 'otherwise' was a matter of chance, and not a matter of a libertarian will changing itself. This way, the Dice Man found a creative response to the question of freedom. As competing egos were freed, so was 'the person.' But no unitary person remained. Uncertainty, it appears, can be engineered, and the experience can be both liberating and frightening. But uncertainty and insecurity are not the same. Whether individuals are comfortable playing the Dice Man's game is for them to find out. Many people will shy away from the experiment, leaving us to conclude that uncertainty and insecurity are empirically related even if they are conceptually distinct. 
As noted before, randomization is the game theorist's defense against exploitation. In the Dice Man's world, by contrast, randomization is a strategy the self can use on itself in order to expand freedom, foster creativity, and find new patches of food and entertainment. The uncertainty that comes with this may breed insecurity but it can be resisted. As E. R. Krüger (personal communication, ca. 1970) noted, we need to overcome our inner pigdog in the interest of personal growth and do what we want (or need) to do even if we are worried about the consequences. Relating the same sentiment in the film A Dangerous Method (Cronenberg, 2011), Otto Gross advises his therapist Carl Jung not to forget to stop for a drink when passing the oasis, transparently implying that Jung should submit to the charms of his patient Sabina Spielrein (Heuer, 2012). Trying to stand on firmer moral ground, conventional psychotherapy takes a similar tack when it recommends confrontation. Under some conditions, confrontation with a feared unknown is necessary for learning and the mitigation of fear (Meuret et al., 2012; see also Garfinkel, 1964, for an analysis of mildly non-normative behaviors in everyday life). In the context of behavioral research, experimenters may choose to expose themselves to alternate treatments and experiences before they subject their subjects to them (Roberts \& Neuringer, 1998). Humans, like pigeons, can learn how to produce, without dice, sequences of behavior that are statistically indistinguishable from the truly random.

The act-different strategy, while liberating, can also signal resentment or ressentiment (Reginster, 2021). In a classic contribution to social psychology, Brehm (1966) introduced the concept of reactance. Reasoning that people seek to protect their freedom of action, they might choose options of low value as long as that choice signals to themselves and others that they are not slaves to the demands of others or the dictates of instrumental rationality. Dostoevsky raised reactance to a principle to live by. In The Gambler (1866/1887), he asserted that he'd rather roam the Kalmyk steppes and sleep in yurts than "bow to the German idol," by which he meant the prudential work ethic, thrift, and general joylessness (see Scheler, 1916, for a corroborating analysis). Though it might create a sense of freedom and self-determination, spite does not make a person unpredictable or unintelligible. Karl Popper (1957) talked of the "Oedipus effect" to refer to a paradoxical linkage between prediction and behavior. If the prophesy (i.e., the prediction) is that Oedipus will kill his 
father, and he vows not to do it, there is still a perfect, though negative, correlation between prediction and intent. When intent and behavior are reactions to prediction, they are not independent of it (Sherman, 1980). This argument does not require the ultimate fulfillment of the prophesy (if that happens, you get an Oedipus Complex).

\section{Conclusion}

At the end of our foraging excursion into the tangled thicket of uncertainty, randomness, and freedom, we can ask what it is that people might want if they desire to feel less insecure. Would it not be nice to have one's freedom of the will assured while having no uncertainties, being faced with guileless opponents and trustworthy friends, and all the while being smarter than both? This, of course, is an idle dream, and one should beware of what one wishes for. An utopian state of psychological security leaves no room for learning, surprising victories (or defeats), or incentives to break new ground by breaking the old box. What we can say is that the interplay of the various forces we have considered is open to introspection and tractable in scientific study. Decisions as to how to apply these lessons rest with the individual. This is an existential freedom we would not want to take away. 


\section{References}

Berg, J., Dickhaut, J., \& McCabe, K. (1995). Trust, reciprocity, and social-history. Games and Economic Behavior, 10(1), 122-142. https://doi.org/10.1006/game.1995.1027

Brehm, J. W. (1966). A Theory of Psychological Reactance. New York: Academic Press.

Buhr, K., \& Dugas, M. J. (2002). The intolerance of uncertainty scale: psychometric properties of the English version. Behavior Research and Therapy, 40(8), 931-945. https://doi.org/10.1016/ S0005-7967(01)00092-4

Cioran, E. (2012/1973). The trouble with being born. Arcade. Original published in French.

Clement, R. W., \& Krueger, J. (1998). Liking persons versus liking groups: A dual-process hypothesis. European Journal of Social Psychology, 28(3), 457-469. https://doi.org/10.1002/ (SICI)1099-0992(199805/06)28:3<457::AID-EJSP880>3.0.CO;2-T

Cronenberg, D. (2011). A dangerous method. https://www.imdb.com/title/tt1571222/

Denrell, J. (2005). Why most people disapprove of me: Experience sampling in impression formation. Psychological Review, 112(4), 951-978. https://doi.org/ 10.1037/0033-295X.112.4.951

Denrell, J., \& Le Mens, G. (2012). Social judgments from adaptive samples. In J. I. Krueger (Ed.), Social Judgment and Decision Making (pp. 151-169). New York: Psychology Press.

Dixit, A. K., \& Nalebuff, B. (2008). The Art of Strategy: A Game Theorist's Guide to Success in Business \& Life. New York: Norton \& Company.

Dostoevsky, F. (1866/1887). The Gambler. London: Vizetelly \& Co..

Evans, A. M., \& Krueger, J. I. (2009). The psychology (and economics) of trust. Social and Personality Psychology Compass: Intrapersonal Processes, 3(6), 1003-1017. https://doi.org/ 10.1111/j.1751-9004.2009.00232.x

Evans, A. M., \& Krueger, J. I. (2016). Bounded prospection in dilemmas of trust and reciprocity. Review of General Psychology, 20, 17-28. doi.org/10.1037/gpr0000063

Fiedler, K., \& Krueger, J. I. (2012). More than an artifact: Regression as a theoretical construct. In J. I. Krueger (Ed.). Social Judgment and Decision Making (pp. 171-189). New York: Psychology Press. 
Fisher, L. (2008). Rock, Paper, Scissors: Game Theory in Everyday Life. New York: Basic Books.

Fiske, S. T., \& Taylor, S. E. (1984). Social cognition. New York: Random House.

Garfinkel, H. (1964). Studies of the routine grounds of everyday activities. Social Problems, 11(3), 225-250. https://doi.org/798722

Genschow, O., \& Lange, J. (2022). Belief in free will is related to internal attribution in selfperception. Social Psychological and Personality Science. https://doi.org/ $10.1177 / 19485506211057711$

Gigerenzer, G. (2015). Risk savvy: How to make good decisions. Penguin.

Gigerenzer, G. (2020). How to explain behavior? Topics in Cognitive Science, 12(4), 1363-1381. https://doi.org/10.1111/tops. 12480

Gigerenzer (2022). How to stay smart in a smart world: Why human intelligence still beats algorithms. MIT Press.

Gold, N., \& Colman, A. M. (2020). Team reasoning and the rational choice of payoff-dominant outcomes in games. Topoi, 39, 305-316. https://doi.org/10.1007/s11245-018-9575-z

Grüning, D. J., \& Krueger, J. I. (2021). Strategic thinking: A random walk into the rabbit hole. Collabra: Psychology, 7(1), 24921. https://doi.org/10.1525/collabra.24921

Grüning, D. J., \& Krueger, J. I. (in preparation). Elements of free will belief: Self-enhancement, uncertainty intolerance, and self-other similarity. Manuscript submitted for publication.

Grüning, D. J., \& Salmen, K. (2021). Metacognition as monitoring and control of the cognitionenvironment fit: A lens model perspective. The Brunswik Society Newsletter 2021, 36, $33-35$.

Hertwig, R., \& Engel, C. (2020) Deliberate ignorance: Choosing not to know. Strüngmann Forum Reports, 29, 257-287. Cambridge, MA: MIT Press.

Heuer, G. M. (2012). A most dangerous - and revolutionary - method: Sabina Spielrein, Carl Gustav Jung, Sigmund Freud, Otto Gross, and the birth of intersubjectivity. Psychotherapy and Politics International, 10(3), 261-278. https://doi.org/10.1002/ppi.1281

Kahneman, D., Sibony, O., \& Sunstein, C. R. (2021). Noise: A Flaw in Human Judgment. New York: Little, Brown Spark. 
Karakowsky, L., Podolsky, M., \& Elangovan, A. R. (2020). Signaling trustworthiness: the effect of leader humor on feedback-seeking behavior. Journal of Social Psychology, 160, 170-189. doi: $10.1080 / 00224545.2019 .1620161$

Knight, F. (1921). Risk, Uncertainty and Profit (vol. XXXI). Boston: Houghton Mifflin.

Krueger, J. I. (2007a). The flight from reasoning in psychology. Behavioral and Brain Sciences, 30(1), 32-33. https://doi.org/10.1017/S0140525X07000751

Krueger, J. I. (2007b). From social projection to social behaviour. European Review of Social Psychology, 18(1), 1-35. https://doi.org/10.1080/10463280701284645

Krueger, J. I. (2010). Beyond free will and determinism: Take a chance with the Dice Man. Psychology Today Online. https://www.psychologytoday.com/us/blog/one-among-many/ 201009/beyond-free-will-and-determinism

Krueger, J. I. (2014). Heuristic game theory. Decision, 1, 59-61.

Krueger, J. I. (2022). The quixotic quest for certainty. Psychology Today Online. https:// www.psychologytoday.com/us/blog/one-among-many/202202/the-quixotic-quest-certainty. Retrieved 3/4/2022

Krueger, J. I. (in press). Nietzsche's last will. Review of 'The will to nothingness. An essay on Nietzsche's On the genealogy of morality' by Bernard Reginster. American Journal of Psychology.

Krueger, J. I. (in press). Twilight of human judgment. Review of 'Noise: A flaw in human judgment' by Daniel Kahneman, Olivier Sibony, \& Cass R. Sunstein. American Journal of Psychology.

Krueger, J. I., \& Evans, A. M. (2013). Fiducia: Il dilemma sociale essenziale / Trust: The essential social dilemma. In-Mind: Italy, 5, 13-18. http://www.tonymevans.com/wp-content/uploads/ 2015/07/krueger-evans-2013.pdf

Krueger, J. I., Heck, P. R., \& Athenstaedt, U. (2017). The search for the self. In T. Nelson (Ed.). Getting grounded in social psychology: The essential literature for beginning researchers (pp. 15-36). New York: Routledge.

Krueger, J. I., \& Grüning, D. J. (2021). Psychological perversities and populism. In J. P. Forgas, W. D. Crano, \& K. Fiedler (eds.). The social psychology of populism: The tribal challenge to 
liberal democracy. The Sydney Symposium on Social Psychology, 22, 125-142. Taylor \& Francis.

Krueger, J. I., Hahn, U., Ellerbrock, D., Gächter, S., Hertwig, R., Kornhauser, L. A., Leuker, C., Szech, N., \& Waldmann, M. R. (2020). Normative implications of deliberate ignorance. In R. Hertwig \& C. Engel (Eds.) Deliberate ignorance: Choosing not to know. Strüngmann Forum Reports, 29, 257-287. Cambridge, MA: MIT Press.

Krueger, J. I., Heck, P. R., Evans, A. M., \& DiDonato, T. E. (2020). Social game theory: Preferences, perceptions, and choices. European Review of Social Psychology, 31, 322-353

Krueger, J. I., Massey, A. L., \& DiDonato, T. E. (2008). A matter of trust: From social preferences to the strategic adherence to social norms. Negotiation \& Conflict Management Research, 1, 31-52. doi:10.1111/j.1750-4716.2007.00003.x

Krueger, J. I., Vogrincic-Haselbacher, C., \& Evans, A. M. (2019). Towards a credible theory of gullibility. In J. P. Forgas \& R. F. Baumeister (eds.). The social psychology of gullibility: Fake news, conspiracy theories, and irrational beliefs. The Sydney Symposium of Social Psychology, 20, 103-122. New York: Psychology Press.

Krueger, J. I., Grüning, D. J., \& Sundar, T. (2022). Power and sociability. In J. P. Forgas, W. D. Crano, \& K. Fiedler (eds.), The psychology of sociability. The Sydney Symposium on Social Psychology, 23. Taylor \& Francis.

MacIntyre, A. C. (1957). Determinism. Mind, 66(261), 28-41.

Meuret, A. E., Wolitzky-Taylor, K. B., Twohig, M. P., \& Craske, M. G. (2012). Coping skills and exposure therapy in panic disorder and agoraphobia: latest advances and future directions. Behavior Therapy, 43(2), 271-284. https://doi.org/10.1016/j.beth.2011.08.002

Morgan, S. L. (2014). Counterfactuals and Causal Inference. Cambridge: Cambridge University Press.

Murray, S., Murray, E., \& Nadelhoffer, T. (2021). Piercing the smoke screen: Dualism, free will, and Christianity, Journal of Cognition and Culture, 21(1-2), 94-111. Doi: https://doi.org/ $10.1163 / 15685373-12340098$ 
Nadelhoffer, T., Shepard, J., Nahmias, E., Sripada, C., \& Thompson Ross, L. (2014). The free inventory: Measuring beliefs about agency and responsibility. Consciousness and Cognition, 25, 27-41. https://doi.org/10.1016/j.concog.2014.01.006

Pinker, S. (2021). Rationality. London: A. Lane.

Pleasants, N. (2019). Free will, determinism, and the "problem" of structure and agency in the social sciences. Philosophy of the Social Sciences, 49(1), 3-30. DOI: 10.1177/0048393118814952

Popper, K. R. (1957). The poverty of historicism. New York: Harper and Row.

Prager, J., Krueger, J. I., \& Fiedler, K. (2018). Towards a deeper understanding of impression formation: New insights gained from a cognitive-ecological analysis. Journal of Personality and Social Psychology, 115(3), 379-397. https://doi.org/10.1037/pspa0000123

Reginster, B. (2021). The will to nothingness. Oxford University Press.

Rhinehart, L. (1971). The Dice Man. Overlook Press.

Roberts, S., \& Neuringer, A. (1998). Self-experimentation. In K. A. Lattal \& M. Perone (Eds.), Handbook of Research Methods in Human Operant Behavior (pp. 619-655). New York: Plenum.

Roese, N. (1999). Counterfactual thinking and decision making. Psychonomic bulletin \& review, 6(4), 570-578. https://doi.org/10.3758/BF03212965

Sarkissian, H., Chatterjee, A., De Brigard, F., Knobe, J., Nichols, S., \& Sirker, S. (2010). Is belief in free will a cultural universal?. Mind \& Language, 25(3), 346-358. https://oi.org/10.1111/ j.1468-0017.2010.01393.x

Seth, A. (2021). Being You: A New Science of Consciousness. London: Faber \& Faber.

Scheler, M. (1917). Über die Ursachen des Deutschenhasses. Leipzig: Wolff.

Schelling, T. C. (1960). The Strategy of Conflict. Boston: Harvard University Press.

Schimmel, S. (1977). Free-will, guilt and self-control in rabbinic Judaism and contemporary psychology. Judaism, 26(4), 418-429.

Sherman, S. J. (1980). On the self-erasing nature of errors of prediction. Journal of Personality and Social Psychology, 39(2), 211-221. https://doi.org/10.1037/0022-3514.39.2.211 
Stephens, D.W., Brown, J.S., \& Ydenberg, R.C. (2007). Foraging: Behavior and Ecology. Chicago: University of Chicago Press.

von Horváth, Ö. (1929/1978). Rund um den Kongreß. In Gesammelte Werke / Bd. 3, Lyrik; Prosa; Romane. Suhrkamp.

von Neumann, J., \& Morgenstern, O. (1947). Theory of games and economic behavior. Princeton, NJ: Princeton University Press.

Westfal, M., Crusius, J., \& Genschow, O. (2021). Imitation and interindividual differences: Belief in free will is not related to automatic imitation. Acta Psychologica, 219, 103374. https:// doi.org/10.1016/j.actpsy.2021.103374 


\section{Appendix}

\section{Appendix A}

Exhaustive presentation of the formula for posterior gain of certainty:

$p(T) \times \frac{p(T) \times p(r \mid T)}{p(r)}+(1-p(T)) \times \frac{p(T) \times p(-r \mid T)}{1-p(r)}-p(T)$

Averaging as an alternative weight of posterior certainties:

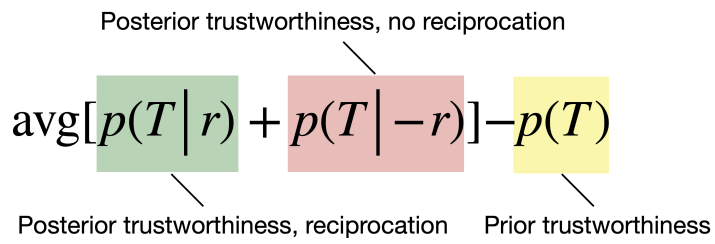

\section{Appendix B}

Free Will Inventory (Nadelhoffer et al., 2014)

1. People always have the ability to do otherwise.

2. People always have free will.

3. How people's lives unfold is completely up to them.

4. People ultimately have complete control over their decisions and their actions.

5. People have free will even when their choices are completely limited by external circumstances.

6. People's choices and actions must happen precisely the way they do because of the laws of nature and the way things were in the distant past.

7. Human action can only be understood in terms of our souls and minds and not just in terms of our brains.

8. Each person has a non-physical essence that makes that person unique.

9. The human mind cannot simply be reduced to the brain.

10. The human mind is more than just a complicated biological machine. 
Scale:

1 - Completely disagree

2

3 - Neither

4

5 - Completely agree

Intolerance of Uncertainty Scale (Buhr \& Dugas, 2002)

1. Unforeseen events upset me greatly.

2. It frustrates me not having all the information I need.

3. Uncertainty keeps me from living a full life.

4. One should always look ahead so as to avoid surprises.

5. A small unforeseen event can spoil everything, even with the best of planning.

6. When it's time to act, uncertainty paralyses me.

7. When I am uncertain I can't function very well.

8. I always want to know what the future has in store for me.

9. I can't stand being taken by surprise.

10. The smallest doubt can stop me from acting.

11. I should be able to organize everything in advance.

12. I must get away from all uncertain situations.

Scale:

1 - Not at all characteristic of me

2 - A bit characteristic of me

3 - Somewhat characteristic of me

4 - Very characteristic of me

5 - Entirely characteristic of me 